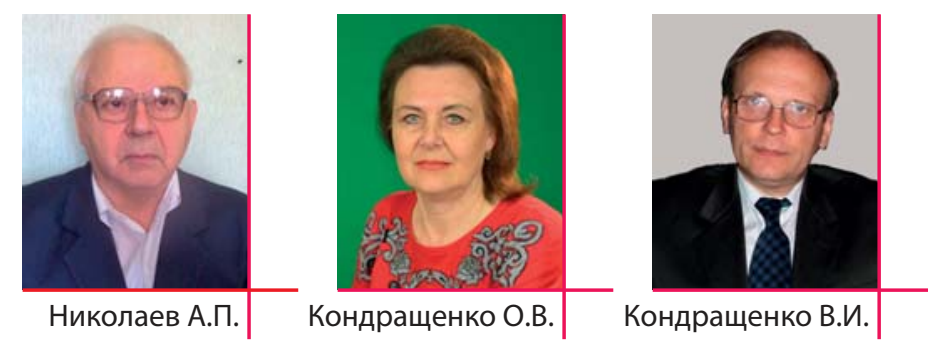

Николаев А. П., канд. техн. наук, инженер кафедры технологии строительного производства и строительных материалов, Харьковский национальный университет городского хозяйства имени А. Н. Бекетова

ул. Маршала Бажанова, 17, г. Харьков, 61002, Украина ॰ (038) $0668605966 \bowtie$ apnikolaev1946@gmail.com

Кондращенко О. В., д-р техн. наук, профессор, зав. кафедры технологии строительного производства и строительных материалов, Харьковский национальный университет городского хозяйства имени А. Н. Бекетова ул. Маршала Бажанова, 17, г. Харьков, 61002, Украина ๘+(038) $0503024822 \bowtie$ zalesk@gmail.com Кондращенко В. И., д-р техн. наук, профессор, кафедра строительные материалы и технологии, Российский университет транспорта (МИИТ) ॰+7 (926) $2118417 \bowtie$ kondrashchenko@mail.ru
A. Nikolaev, Kand. Tech. sciences,

Engineer of the Department of Technology of Building Production and Building Materials,

A. H. Beketov National University of Urban Economy in Kharkov,

st. Marshal Bazhanov, 17, Kharkiv, 61002, Ukraine

\&+ (038)0668605966凶apnikolaev1946@gmail.com

E. Kondrachenko, Dr. Tech. Sciences, Professor,

head. Chair of Technology of Building Production

and Building Materials, A. H. Beketov National University

of Urban Economy in Kharkov,

st. Marshal Bazhanov, 17, Kharkiv, 61002, Ukraine

\$+ (038)0503024822凶zalesk@gmail.com

V.Kondrashchenko, Dr. Tech. Sciences,

professor of Department Building Materials and Technologies,

Russian University of Transport (MIIT)

¿7(926)2118417凶kondrashchenko@mail.ru

\title{
ПОТРЕБИТЕЛЬСКИЕ СВОЙСТВА ПОРТЛАНДЦЕМЕНТА
}

\section{СПОЖИВЧІ ВЛАСТИВОСТІ ПОРТЛАНДЦЕМЕНТУ} CONSUMER PROPERTIES OF PORTLANDCEMENT

Анотация. Обоснована целесообразность проведения дополнительного входного контроля структурообразующей способности портландцемента на предприятиях по изготовлению бетонных и железобетонных изделий с использованием методов пластометрии и экспресспрогноза вяжущей активности.

Ключевые слова: вяжущая активность, цементное тесто, предельное напряжение сдвига, сроки схватывания, пластометрия. Анотація. Обґрунтовано доцільність проведення додаткового вхідного контролю структуроутворюючої здатності портландцементу на підприємствах з виготовлення бетонних і залізобетонних виробів з використанням методів пластометрії і експрес-прогнозу в'яжучої активністі. Ключові слова: цементне тісто, максимальне напруження зсуву, терміни тужавіння, пластометрія.

Annotation. The expediency of carrying out the entrance control of the structure-forming ability of Portland cement at enterprises for the production of concrete and reinforced concrete products using plastometry methods and express forecast of astringent activity is substantiated. Keywords: knitting activity, cement dough, ultimate shear stress, setting time, plastometry.

\section{Введение}

К наиболее значимым для потребителей свойствам портландцемента (ПЦ) относят его структурообразующую способность при схватывании и вяжущую активность при твердении [1]. От динамики схватывания цементного теста зависят параметры технологического режима приготовления, формовки и последующей переработки бетонных смесей, а от вяжущей активности - расход цемента [2]. Отсюда следует, что если не уделять достаточного внимания входному контролю потребительских свойств ПЦ, то, как правило, это приводит к его перерасходу и снижению качества выпускаемой продукции.

Как известно, вяжущая активность ПЦ зависит от его дисперсности, вещественного и химико-минералогического состава, и уровня нарушений структурной упорядоченности фазообразующих минералов [3]. Варьируя соотношения между указанными параметрами, можно получать ПЦ со специальными свойствами и обеспечивать требуемый уровень его вяжущей активности [4,5]. Практика показывает, что на заводах по производству ПЦ одинаковый уровень его активности достигают различным соотношением между основностью клинкера, его содержанием в конечной продукции и дисперсностью. По этой причине цементы одного класса от разных производителей отличаются своими потребительскими свойствами, а именно водопотребностью, начальной динамикой взаимодействия с водой, реакцией на одни и те же химические добавки и т. д. Такое положение дел усложняет работу по освоению по- ступающего цемента на предприятиях, выпускающих бетонные и железобетонные изделия. Авторы считают, что введение на этих предприятиях дополнительного входного контроля структурообразующей и вяжущей способности ПЦупростит их работу и будет способствовать повышению стабильности качества выпускаемой продукции.

\section{Цель исследований}

Обеспечить повышение стабильности качества продукции на предприятиях по производству всех видов изделий на основе портландцемента за счет внедрения контроля его потребительских свойств с использованием методов пластометрии и экспресс-прогноза вяжущей активности.

\section{Аппаратура и методы}

Пластометрия

На предприятиях строительной индустрии для контроля пластических свойств ПЦ используют прибор Вика, с помощью которого определяют нормальную густоту цементного теста (НГТ) и сроки схватывания при водоцементном отношении (В/Ц) равном НГТ [6]. Однако для анализа поведения цементного теста при других условиях этот прибор не предназначен. В тоже время наличие такой информации позволяет решить многие проблемы при использовании ПЦ, особенно для производителей бетона и железобетона. Для контроля пластических свойств цементного теста в широком диапазоне условий его схватывания наиболее пригоден конусный пласто- 
метр. Это известное устройство, разработанное в свое время академиком П. А. Ребиндером [7], успешно использовалось В. С. Данюшевским при исследовании пластических свойств тампонажных цементов [8] и В. Д. Глуховским с сотрудниками при изучении динамики схватывания шлакощелочных вяжущих [9].

С учетом того, что при входном контроле необходимо дифференцировать ПЦ, в том числе и с близкими структурообразующими свойствами, авторы модифицировали пластометр в части повышения точности измерения контролируемых параметров, о чем подробно изложено в работе [10].

Метод прогнозирования активности чемента

В дополнение к пластометрическому контролю авторы предлагают потребителям ПЦ использовать оригинальную методику прогнозирования активности цемента, суть которой подробно изложена ими в монографии [9]. Методика основана на определении количества кальция, который способен перейти из ПЦ в жидкую фазу в составе продуктов гидродеструкции его минералов при определенных стандартных условиях. Идея прогноза состоит в том, что это количество кальция, как, и вяжущая активность ПЦ, зависит от одних и тех же ранее упомянутых параметров анализируемого материала, а именно его дисперсности, вещественного и химико-минералогического состава, а также структурной упорядоченности фазообразующих минералов. Условия проведения анализа подобраны таким образом, чтобы за время его осуществления успело прореагировать не менее трети ПЦ способного участвовать в формировании его марочной прочности. В связи с этим для обозначения контролируемого кальция авторы предлагают термин «марочный кальций». Использование кальция в качестве индикатора вяжущей активности ПЦ обосновано тем, что он входит в состав всех исходных и конечных соединений твердеющей цементной системы [11].

В рассматриваемой методике устраняется главный недостаток существующих экспресс-методов прогноза физико-механической активности ПЦ, основанных на анализе поведения цемента, когда его основные фазы практически еще не вступили в реакцию с водой [12].

\section{Результаты исследования}

Изучение потребительских свойств цемента проводили на пробах, представляющих продукцию 5 предприятий (табл. 1).

При исследовании цементы группировали и сравнивали их свойства или с одинаковой марочной прочностью, но от разных производителей, или с разной марочной прочностью от одного и того же производителя. Такой подход был выбран для того, чтобы наглядно продемонстрировать необходимость входного контроля цемента, если его потребители стремятся к высокому качеству своих изделий или заинтересованы в снижении их себестоимости. На рис. 1 приведены пластограммы цементов марки 500 разных производителей при В/Ц = 0,28 отн. ед.

Кривые на рис. 1 свидетельствуют о различии структурообразующей способности анализируемых цементов одного класса от разных производителей, что подтверждает необходимость контроля ПЦ для уточнения режима подготовки и переработки бетонных смесей при его использовании.

Поведение анализируемых цементов продемонстрировало их индивидуальность уже в период подготовки. Так было отмечено заметное схватывание цемента № 1 непосредственно в процессе его пятиминутного вымешивания. С целью определения интенсивности этого процесса был изменен порядок пробоподготовки. Пробы № 1 и 2 перемешивали только 1 минуту, после чего полученное тесто укладывали в форму на вибростоле в течение еще одной минуты. Затем проводили измерение пластической прочности сразу после укладки и через определенные промежутки времени (рис. 2).

Как видно из рис. 2, при использованном режиме вымешивания у пробы 1 (Белорусский цемент) происходит значительное схватывание уже в первые минуты гидратации. Использование такого анализа позволит более обосновано и внимательно относится к подбору режима подготовки бетонных смесей при работе с цементом.

На рис. 3 показана динамика структурирования цементов марки 400 от разных производителей при В/Ц = 0,27.

Анализ рис. 3 показывает значительное отличие цементов 6 и 7 по динамике их взаимодействия с водой, хотя они и относятся к одному классу прочности. А это значит, что такие цементы требуют индивидуального подхода при их использовании, что получило подтверждение при введении в них пластифицирующей добавки. На рис. 4 показано влияние пластификатора СП1-ВП на динамику структурирования этих цементов при В/Ц =0,27. В цементы 6 и 7 было введено 0,1 и 0,3 \% этого пластификатора, соответственно.

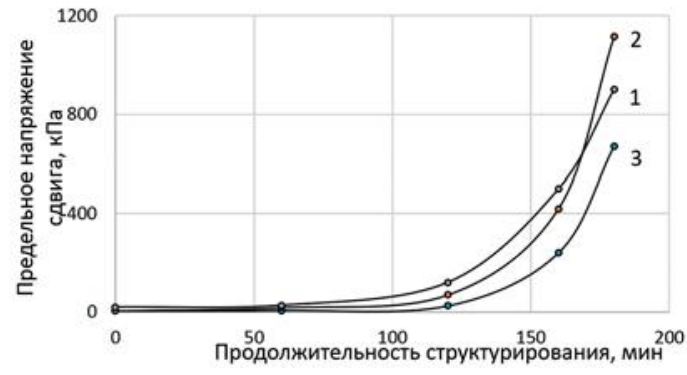

Рис. 1. Пластограммы цементов:

1 - Белорусь-цемент;

2 - Юг цемент;

3 - Ивано-Франковскцемент

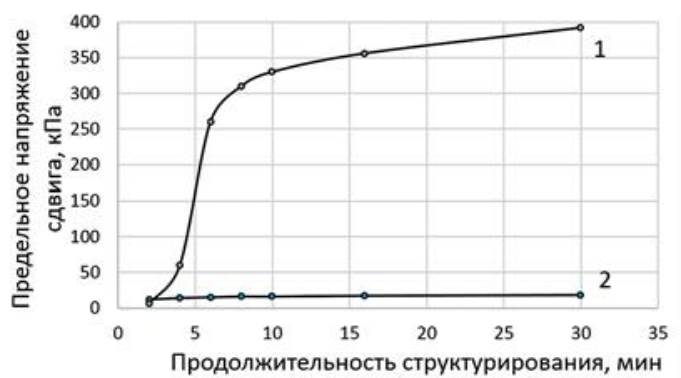

Рис. 2. Пластограммы цементов марки 500:

1 - Беларусь-цемент,

2 - Ивано-Франковскцемент

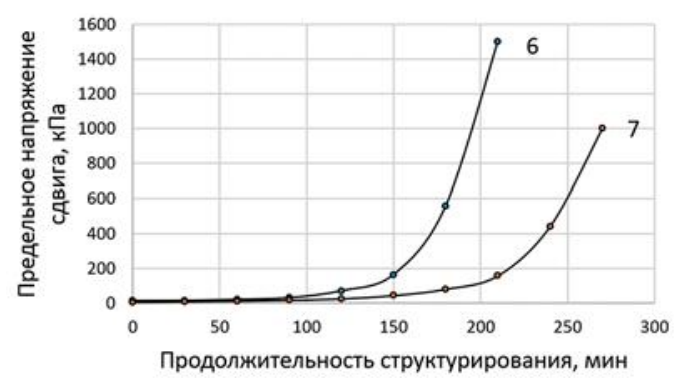

Рис. 3. Изменение величины предельного напряжения сдвига в процессе схватывания (номера кривых соответствуют нумерации цементов таблицы 1)

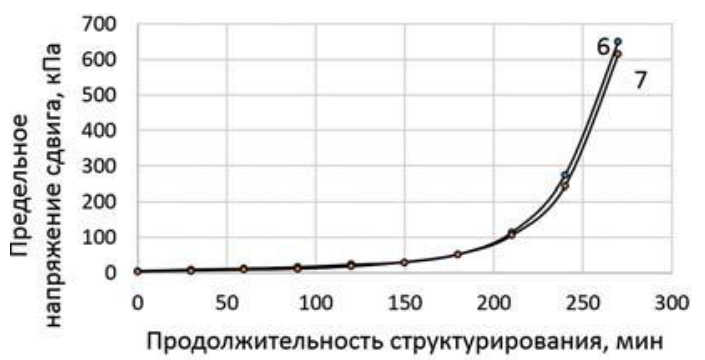

Рис. 4. Пластограммы цементов с пластифицирующей добавкой (номера кривых соответствуют нумерации табл. 1)

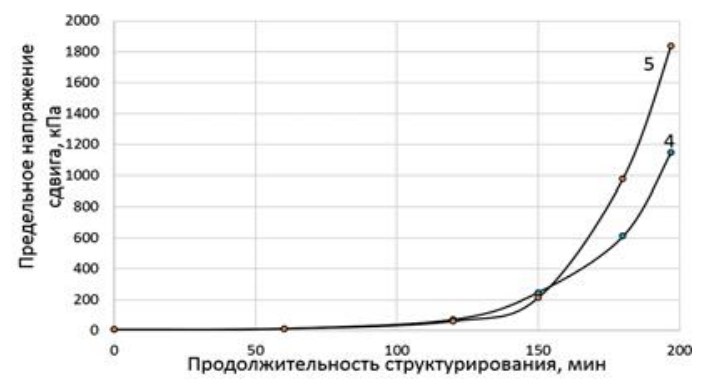

Рис. 5. Пластограммы Криворожского цемента (номера кривых соответствуют нумерации табл. 1) 
Анализируемые цементы

\begin{tabular}{|c|c|c|}
\hline$\Pi / \boldsymbol{n}$ & Индекс цемента & Производитель \\
\hline 1 & ПЦ II/А-Ш-500 & Белорусь-цемент \\
\hline 2 & ПЦ 500 Д0 & «Дикергофф Цемент Украина», Юг цемент \\
\hline 3 & ПЦІ І-500 & «Ивано-Франковскцемент» \\
\hline 4 & ПЦ ІІ/А-Ш-400 проба I & \multirow{2}{*}{ «Хайдельберг цемент», Кривой Рог } \\
\hline 5 & ПЦ II/А-Ш-400 проба II & \\
\hline 6 & ПЦ II АШ 400 R & «Евроцемент», Балцем \\
\hline 7 & ПЦ II АШ 400 R & «Ивано-Франковскцемент» \\
\hline
\end{tabular}

Вяжущий потенциал контролируемых ПЦ

Таблица 2

\begin{tabular}{|c|c|c|}
\hline № $\mathbf{n} / \mathbf{n}$ & Наименование & Содержание СаO, \% \\
\hline 1 & ПЦ I -500 «Ивано-Франковскцемент» & 16,2 \\
\hline 2 & ПЦ 500 Д0 «Дикергофф Цемент Украина», Юг цемент & 15,1 \\
\hline 3 & ПЦ II/А-Ш-500 Белорусь цемент & 14,5 \\
\hline 4 & ПЦ II/А-Ш-400 «Хайдельберг цемент», КривойРог I & 14,0 \\
\hline 5 & ПЦ II/А-Ш-400 «Хайдельберг цемент», Кривой Рог II & 12,9 \\
\hline 6 & ПЦ II/A-Ш 400 R «Евроцемент», Балцем & 11,8 \\
\hline 7 & ПЦ II/А-Ш 400 R»Ивано-Франковскцемент» & 10,1 \\
\hline
\end{tabular}

Проведенный анализ продемонстрировал, что для получения пластифицированного бетона на основе этих цементов количество вводимого пластификатора может отличаться в три раза (рис. 4).

Далее были исследованы цементы из разных партий одного производителя (Кривой Рог), которые отличались временем их поставки потребителю. На рис. 5 представлены пластограммы этих цементов при В/Ц = 0,27.

Из рис. 5 видно, что после 2,5 часов схватывания проба 5 проявила большую активность в структурировании цементного теста, чем проба 4. Из этого следует, что для стабилизации качества бетонной продукции необходим контроль потребительских свойств ПЦ и при работе с цементом от одного и того же производителя.

Для контроля активности цемента авторы использовали свою оригинальную методику [10]. В табл. 2 приведены результаты определения содержания в анализируемых пробах ПЦ марочного кальция (в пересчете на СаO).
Как видно из табл. 2, содержание марочного кальция в изучаемых цементах находится в пределах 10-16\%, что соответствует примерно 30-50 \% от его количества, принимающего участие в формировании их вяжущих свойств, т. е. приведенные данные можно использовать для уточнения расхода цемента в бетоне.

\section{Выводы:}

- проведенные исследования наглядно продемонстрировали необходимость и эффективность использования методов определения пластических и гидратационных свойств цемента для контроля стабильности его качества;

- применение предлагаемых методов анализа позволяет рационально использовать ПЦ, а при необходимости и модификаторы различного спектра действия, избегать их перерасхода и повысить стабильность качества выпускаемой продукции.
Литература:

1. Волженский А..В. Минеральные вяжущие вещества / А. В. Волженский, Ю. С. Буров, В. С. Колокольников. М. : Стройиздат, 1979. -476 с.

2. Адамцевич А. О. Актуальные аспекты практического применения методов калориметрии при изучении кинетики гидратации вяжущих в строительном материаловедении / А. О. Адамцевич // Интеграция, партнерство и инновации в строительной науке и образовании: материалы юбилейной Международной научной конференции, посвященной 95-летию НИУ МГСУ (16-17 ноября 2012 г.). - М. : МГСУ, 2012. - С. 354-360.

3. Юдович Б. Э. Влияние технического уровня производства цемента на его строительно-технические свойства в бетонах. Энергосберегающие технологии при производстве цемента / Б. Э. Юдович, Л. Г. Бернштейн // 2-е Научные чтения по цементу: сб. докладов. СПб: Изд-во НТЦ «Алит» и «Гипроцемент-Наука», 2006. - С. 78-82.

4. Пащенко А. А. Вяжущие материалы /А. А. Пащенко, В. П. Сербин, Е. А. Старчевская. - Киев : Вища школа, 1985. $-440 \mathrm{c}$.

5. Бутт Ю. М. Портландцементный клинкер / Ю. М. Бутт, В. В. Тимашев. - М. : Стройиздат, 1967. - 304 с.

6. ДСТУ Б ЕN 196-3:2015 «Методи випробування цементу. Визначення строків тужавлення та рівномірності зміни об'єму», 2016.
7. Ребиндер П. А. О методе погружения конуса для характеристики структурно-механических свойств пластично-вязких тел / П. А. Ребиндер, Н. А. Семененко // Доклады Академии Наук CCCP, 1949. - T. LXIV - № 6. - С. 835-838.

8. Данюшевский В. С. Справочное руководство по тампонажным материалам / В. С. Данюшевский, Р. М. Алиев, И. Ф. Толстых. - М. : Недра, 1987. - 373 с.

9. Runova, R. Formation of plastic strength of slag-alkaline cement pastes with polyols / R. Runova, I. Rudenko, V. Skorik // In Proc. of the International Conference on Quality Strategy in Industry and Education. - Varna, Bulgaria, 2013.

10. Николаев А. П. Вяжущие свойства портландцемента. Контроль и анализ / А. П. Николаев, Е. В. Кондращенко. - Харьков: ХНУГХ им. А. Н. Бекетова, 2017. - 80 с.

11. Николаев А. П. Совершенствование методов контроля свойств материалов цементного производства / А. П. Николаев, Е. В. Кондращенко, А. И. Здоров, М. М. Кузнецова // Збірник наукових праць Українського державного університету залізничного транспорту. - Харків : УкрДУЗТ, 2016. - Вып. 160. - С. 53-58.

12. Головин В. В. Методы и приборы определения активности цемента / В. В. Головин, К. П. Латышенко, В. С. Цикунов // Известия МГТУ «МАМИ»: журнал. - М. : Московский государственный машиностроительный университет (МАМИ), 2013. - Т. 2. - № 3 (17). - С. 201-205. 